Davis, J. C. \& Mudd, S. (1956). J. gen. Microbiol. 14, 527-532

\title{
Gytological Effects of Ultraviolet Radiation and Azaserine on Corynebacterium diphtheriae
}

\author{
By J. C. DAVIS AND S. MUDD \\ Department of Microbiology, School of Medicine, University of Pennsylvania, \\ Philadelphia 4, Pa, U.S.A.
}

SUMMARY: Ultraviolet irradiation and the radiomimetic antibiotic substance L-azaserine have similar effects in promoting the formation of radially enlarged cells and elongated filaments, and in the accumulation of metaphosphate in metachromatic granules, with a strain of Corynebacterium diphtheriae. Dosages effective for the formation of enlarged cells and filaments are lower than for stimulation of metaphosphate accumulation.

Attention has been directed to parallel effects on bacterial cells of ultraviolet radiation and of certain radiomimetic substances which possess carcinogenic or oncolytic action (Lwoff, 1953; Kellenberger, 1953). Similar parallel effects may now be cited for u.v. radiation and L-azaserine (o-diazoacetylserine), an antibiotic substance which has anti-neoplastic properties (Stock, Reilly, Buckley, Clarke \& Rhodes, 1954). Azaserine is mutagenic (Demerec et al. 1954), capable of inducing filament formation in Escherichia coli (Maxwell \& Nickel, 1954), and of inducing development of lytic phage in lysogenic $E$. coli, strain K-12 (Gots, Bird \& Mudd, 1955). The present communication is concerned with the cytological effects of u.v. radiation and azaserine on Corynebacterium diphtheriae.

\section{METHODS}

A mitis strain, A 9255, of Corynebacterium diphtheriae, whose cytology has been studied in detail (Davis \& Mudd, 1955) was used throughout. Organisms were initially grown for approximately $18 \mathrm{hr}$. in M. \& E. (Morton \& Engley, 1945) broth containing $5 \%$ horse blood serum, and at the time of treatment with u.v. radiation or azaserine, lacked metachromatic granules or were poorly metachromatic.

The phenomena to be described were observed following irradiation of organisms, either suspended in $10 \mathrm{ml}$. of various solutions in Petri dishes (saline, phosphate, sucrose, distilled water or Tris buffer (2-amino-2-hydroxy methyl-1.3 propandiol, obtained from Sigma Chemical Co., St Louis 13, Missouri)), dried down on agar plates, or initially lyophilized and the dry organisms spread on Petri dishes for irradiation prior to reconstitution in distilled water. Organisms were also exposed to various concentrations of azaserine diluted in Tris buffer, and were then washed and incubated. All organisms were incubated on blood agar after treatment and checked periodically for cytological changes, using Neisser's acidified methylene blue stain.

As a source of u.v. radiation a General Electric germicidal lamp (G 15 T 8) was used whose output is predominantly at $2537 \mathrm{~A}$. The lamp in most of the 
experiments was 18.7 in. from the organisms. Under these conditions the radiation, as measured by a General Electric germicidal u.v. intensity meter 16522, was approximately 105 u.v. $\mathrm{mW}$./sq.ft. (1130 ergs/sec./cm. $\left.{ }^{2}\right)$. In certain experiments the u.v. source was $1 \mathrm{in}$. from the organisms; the intensity of irradiation was then estimated as 2.9 u.v. W./sq.ft. $\left(31,215 \mathrm{ergs} / \mathrm{sec} . / \mathrm{cm} .{ }^{2}\right)$.

Azaserine, kindly supplied by Parke, Davis and Co., was used in the concentrations indicated in Fig. 1 and in the text.

Cytological observations were made with the aid of redox indicators. Suitable concentrations in M. \& E. broth were $0 \cdot 1 \%$ neotetrazolium chloride, $0.02 \%$ blue tetrazolium chloride, $0.05 \%$ potassium tellurite, and $0.002 \%$ Janus green B. Also employed were Sudan black B-citric acid (Davis \& Mudd, 1955), the Hale (1953) cell wall stain, and nuclear stains according to Feulgen and DeLamater (1951).

A modification of the May-Grünwald stain (Hartman \& Payne, 1954) was further modified so as to permit differential staining of nuclei and metachromatic granules in Corynebacterium diphtheriae. The modified procedure is as follows:

(1) Fix coverslip impression smears of organisms overnight in methanol previously chilled on dry ice; transfer for a few seconds to methanol at room temperature.

(2) Stain smears 10 min. in $1: 5$ dilution in methanol of a saturated solution of methylene blue eosinate made up in methanol. (The saturated solution was aged for at least 2 weeks before use.) Rinse in distilled water.

(3) Stain smears $10 \mathrm{~min}$. in 1: 10 Giemsa solution in distilled water. Rinse.

(4) Hold smears $1 \mathrm{~min}$. in $5 \%$ citric acid to remove dense cytoplasmic staining.

(5) Blot, rinse twice in xylol, and mount in Harleco synthetic resin.

\section{RESULTS}

Fig. 1 shows the effects of u.v. irradiation and azaserine upon viability and the formation of radially enlarged organisms and elongated filaments. Pl. 1 shows some of the cytological changes involved. Photographs of azaserine-treated organisms were not included because of similarity to those of irradiated organisms.

Enlarged organisms and filaments. With relatively short periods of irradiation (5-20 sec. at 18.7 in.) cells were apparently unchanged (Fig. 1, curve $A$ ). With longer exposure $(40-120 \mathrm{sec}$.) organisms were observed to undergo elongation which at times was accompanied by enlargement to abnormal size (Pl. 1, fig. 2). Formation of enlarged organisms soon ceased altogether when irradiation times were extended beyond 2 min., and most organisms were unable to produce colonies (Pl. 1, fig. 3). Persistently enlarged organisms could be obtained by exposing organisms to repeated doses of u.v. with intermittent incubation on blood agar (Pl. 1, figs. 4, 5). However, when doses which were optimal for producing, such organisms were used repeatedly, the organisms lost their ability to segment in an orderly fashion and instead showed extensive fragmentation and disintegration. 
Cytological observation of enlarged organisms coloured with either the tetrazoles or potassium tellurite, or stained with Sudan black B-citric acid showed that they contained more redox-active lipid-containing granules than did the normal organisms of smaller size (Pl. 1, figs. $6 a, b)$. Enlarged organisms often lacked septa, although some possessed one or two (Pl. 1, fig. $6 a$ ). Nuclear stains showed that extensive cellular elongation and enlargement was accompanied by dispersion of nuclear material throughout the organisms, either in discrete areas or in long continuous masses which in time might become segmented. The modified May-Grünwald stain was able to distinguish red-staining nuclear material from purple-staining metachromatic granules (Pl. 1, figs. 5, 7-10).

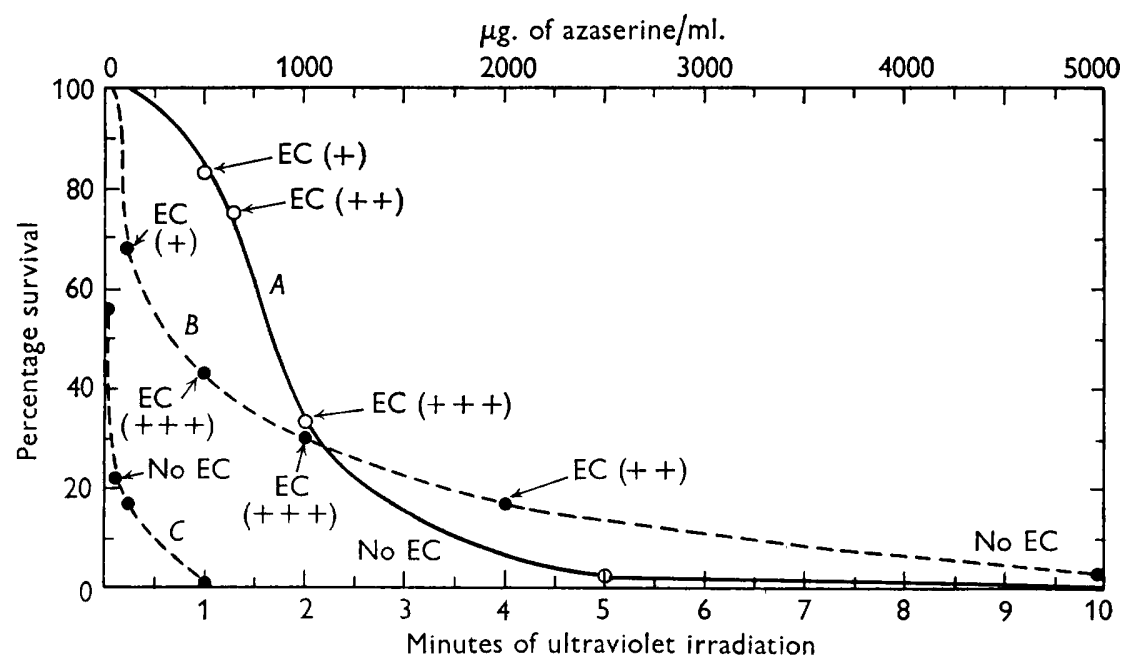

Fig. 1. Corynebacterium diphtheriae, strain mitis A 9255, originally grown $12 \mathrm{hr}$. in blood broth, shows effect of u.v. irradiation and exposure to azaserine upon cell viability, as determined by plate counts, and formation of enlarged cells. Curve $A=$ organisms irradiated with germicidal lamp at $18.7 \mathrm{in}$., then incubated upon blood agar. Curve $B=$ organisms suspended in azaserine solution for $1 \mathrm{hr}$., then washed and incubated on blood agar. Curve $C=$ as $B$ but organisms incubated in azaserine solution for $5 \mathrm{hr}$. $\mathrm{EC}=$ enlarged cell formation as indicated by enlargement and filament formation. ,$++++++=$ degree of such formation.

Treatment of organisms with azaserine for $1 \mathrm{hr}$. (Fig. 1, curve $B$ ) in concentration of $50 \mu \mathrm{g} . / \mathrm{ml}$. did not noticeably affect them. Concentrations of 500-1000 $\mu \mathrm{g} . / \mathrm{ml}$. promoted enlargement and decreased survival rate. Formation of enlarged organisms was less evident at $2000 \mu \mathrm{g} . / \mathrm{ml}$. and absent at $5000 \mu \mathrm{g} . / \mathrm{ml}$. When organisms were exposed to azaserine for $5 \mathrm{hr}$. (Fig. 1, curve $C$ ) there was a rapid loss of viability, $500 \mu \mathrm{g} . / \mathrm{ml}$. killing over $99 \%$, and the ability to produce enlarged organisms was lost.

Metachromatic granules. In organisms irradiated for as long as 100 sec. or more, metachromatic granules were observed to form more rapidly and attain a greater ultimate size than did the granules of normal cells. This induced ability to form prominent granules was retained even when the ability to form enlarged cells and to produce colonies was destroyed (Pl. 1, fig. 3). Metachromatic granules were formed in organisms irradiated for as long as $1 \mathrm{hr}$. 
When enlarged organisms were exposed to graduated doses of radiation, the higher doses favoured formation of metachromatic granules (Pl. 1, fig. 4). Excessive irradiation (e.g. for $40 \mathrm{~min}$. with the radiant source at distance of 1 in.) could diminish or completely suppress metachromatic granule formation. There was a corresponding loss of ability to reduce the tetrazoles, potassium tellurite and Janus green B.

Enlarged organisms and prominent granules were produced when irradiated organisms were incubated either aerobically or anaerobically. The visible cytological effects of u.v. irradiation were practically the same for organisms early in the log phase and late in the stationary phase of growth.

Treatment with azaserine also was able to promote the formation of metachromatic granules. Exposure for $1 \mathrm{hr}$. to $1000 \mu \mathrm{g} . / \mathrm{ml}$. increased metachromatic granule formation; 5000-10,000 $\mu \mathrm{g} . / \mathrm{ml}$. were even more effective. In most organisms treated with large doses of azaserine and incubated on agar for as long as $48 \mathrm{hr}$., prominent metachromatic granules were seen since no normal cells survived to overgrow the agar and obscure the affected organisms.

\section{DISCUSSION}

It seems reasonable to conclude that the formation of enlarged organisms and filaments was the result of inhibition of division without proportionate inhibition of growth in organisms which were injured by u.v. radiation or by azaserine. However, it is as yet unknown how specific, if at all, these agents are with respect to inhibition of division. Certainly the division of other bacteria, e.g. Escherichia coli, can be inhibited by a great variety of agents.

Metachromatic granules in Corynebacterium diphtheriae represent accumulations of metaphosphate (Ebel, 1949; König \& Winkler, 1948). These metaphosphate accumulations are formed and disappear, depending on a variety of conditions (Sall, Mudd \& Davis, 1955). Their appearance is favoured by the presence of an oxidizable substrate of the tricarboxylic acid cycle and by orthophosphate and potassium. The sites of metachromatic granule formation are in loci possessing redox activity according to Mustakallio \& Jännes (1954), who found that these loci in diphtheria organisms reduce Janus green $\mathbf{B}$ and the tetrazoles (although Davis \& Mudd, 1955, were unable to state this conclusively). Ultraviolet radiation and azaserine may affect these granules by either directly or indirectly altering the phosphate metabolism of the cells. Halvorson (1954), working with aerobically and anaerobically growing yeasts, has shown that the uptake and incorporation of inorganic phosphate into acid-insoluble phosphate is favoured by azaserine.

Apparently the mechanisms involving cell division and viability are more vulnerable to the action of $u . v$. radiation and azaserine than are the mechanisms concerning metaphosphate accumulation and redox activities of non-metachromatic (and possibly metachromatic) granules.

What common factor or factors in the interaction of bacteria with u.v. radiation and azaserine may underlie such diverse effects as inhibition of 
cell division, alterations of phosphate metabolism, mutagenesis, and induction of phage maturation, is of course quite unknown. The fact of the association, however, may suggest some clues for further investigation.

This work has been aided by a grant from the United States Atomic Energy Commission, AEC Contract no. A'T (30-1)-1342.

\section{REFERENCES}

Davis, J. C. \& Mudd, S. (1955). The cytology of a strain of Corynebacterium diphtheriae. J. Bact. 69, 413.

Delamater, E. D. (1951). A new staining and dehydrating procedure for the handling of microorganisms. Stain Tech. 26, 199.

Demerec, M., Moser, H., Hemmerly, J., Blomstrand, I., Demerec, Z. E., FitzGerald, P. L., Glover, S. W., Hanson, J. F., Nielsen, F. J. \& Yura, T. (1954). Bacterial genetics. 1. Yearb. Carneg. Instn, 53, 225.

Ebel, J. P. (1949). Participation de l'acide métaphosphorique à la constitution des bactéries et des tissus animaux. C.R. Acad. Sci., Paris, 228, 1312.

Gots, J. S., Bird, T. J. \& Mudd, S. (1955). L-azaserine as an inducing agent for the development of phage in the lysogenic Escherichia coli, K-12. Biochim. biophys. Acta, 17, 449 .

Hale, C. M. F. (1953). The use of phosphomolybdic acid in the mordanting of bacterial cell walls. Lab. Practice, 2, 115.

Halvorson, H. (1954). Some effects of azaserine on yeast metabolism. Antibiot. d Chemother. 4, 948.

Hartman, P. E. \& Payne, J. I. (1954). Direct staining of the two types of nucleoproteins in Escherichia coli. J. Bact. 68, 237.

Kellenberger, E. (1953). Les formes caractéristiques des nucléoides de E. coli et leurs transformations dues à l'action d'agents mutagènes-inducteurs et de bactériophages. In Bacterial Cytology (Symp. Congr. int. Microbiol.), p. 45.

KöNıG, H. \& WinkLer, A. (1948). Ưber Einschlüsse in Bakterien und ihre Veränderung im Electronenmikroskop. Naturwissenschaften, 35, 136.

Lwoff, A. (1953). Lysogeny. Bact. Rev. 17, 269.

Maxwell, R. \& Nicked, V. S. (1954). Filament formation in E. coli induced by azaserine and other antineoplastic agents. Science, 120, 270.

Morton, H. E. \& Engley, F. B., Jun. (1945). The protective action of dysentery bacteriophage in experimental infections in mice. J. Bact. 49, 245.

Mustakallio, K. K. \& JänNes, L. (1954). Intracellular distribution of dehydrogenase activity in C. diphtheriae and in C. pseudodiphtheriticum. Exp. Cell Res. $\mathbf{7}, \mathbf{5 9 5}$.

Sall, T., Mudd, S. \& Davis, J. C. (1955). Factors conditioning the accumulation and disappearance of metaphosphate in cells of Corynebacterium diphtheriae. Arch. Biochem. Biophys. 60, 130.

Stock, C. C., Reilly, H. C., Buckley, S. M., Clarke, D. A. \& Rhodes, C. P. (1954). Azaserine, a new tumour-inhibitory substance. Studies with Crocker mouse sarcoma 180. Nature, Lond. 173, 71 .

\section{EXPLANATION OF PLATE}

Corynebacterium diphtheriae, strain mitis A 9255. Organisms originally grown in blood broth for approximately $18 \mathrm{hr}$. Organisms lacking metachromatic granules were then exposed to u.v. irradiation at 18.7 in. and subsequently incubated on blood agar.

Fig. 1. Non-irradiated organisms on blood agar for $10 \mathrm{hr}$. Granules small. Neisser stain.

Fig. 2. Organisms irradiated for 2 min., then on blood agar for $5 \mathrm{hr}$. After $10 \mathrm{hr}$. these organisms resemble those in fig. 1. Neisser stain. 
Fig. 3. Organisms irradiated for $15 \mathrm{~min}$., then incubated on blood agar for $10 \mathrm{hr}$. Neisser stain.

Fig. 4. Organisms irradiated for $100 \mathrm{sec}$, then on blood agar for $5 \mathrm{hr}$. Irradiated cells again irradiated for 80 sec., then incubated on blood agar for an additional $4 \mathrm{hr}$. With cells only exposed to the first irradiation, enlarged cells and some granulation were evident after $5 \mathrm{hr}$. However, after $9 \mathrm{hr}$. these cells resembled normal cells in fig. 1. Apparently the second irradiation promoted granule and enlarged cell formation. Neisser stain.

Fig. 5. As fig. 4 except stained for nuclear material according to DeLamater using azure A.

Fig. 6a. Organisms irradiated for 100 sec., then on blood agar for $7 \mathrm{hr}$. followed by $1 \mathrm{hr}$. on $0.1 \%$ neotetrazolium chloride agar. Cell wall stained according to Hale. $S=$ septa. Other granules are result of reduction of the tetrazole.

Fig. 6 b. Numerous sudanophilic granules in cells irradiated $80 \mathrm{sec}$., then on blood agar for $7 \mathrm{hr}$.

Fig. 7. Nuclei in non-irradiated, non-metachromatic cells prior to incubation on blood agar. Modified May-Grünwald stain.

Fig. 8a, b. Organisms irradiated for 100 sec., then on blood agar for $7 \mathrm{hr}$. Modified MayGrünwald stain. $m=$ metachromatic granule; $n=$ nuclear material.

Fig. 9. Organisms irradiated $5 \mathrm{~min}$., then on blood agar $12 \mathrm{hr}$. Modified May-Grünwald stain. Central, faintly staining areas are nuclear.

Fig. 10. Non-irradiated organisms on blood agar for $12 \mathrm{hr}$. Modified May-Grünwald stain. $m=$ metachromatic granule; $n=$ nuclear material.

(Received 27 September 1955) 


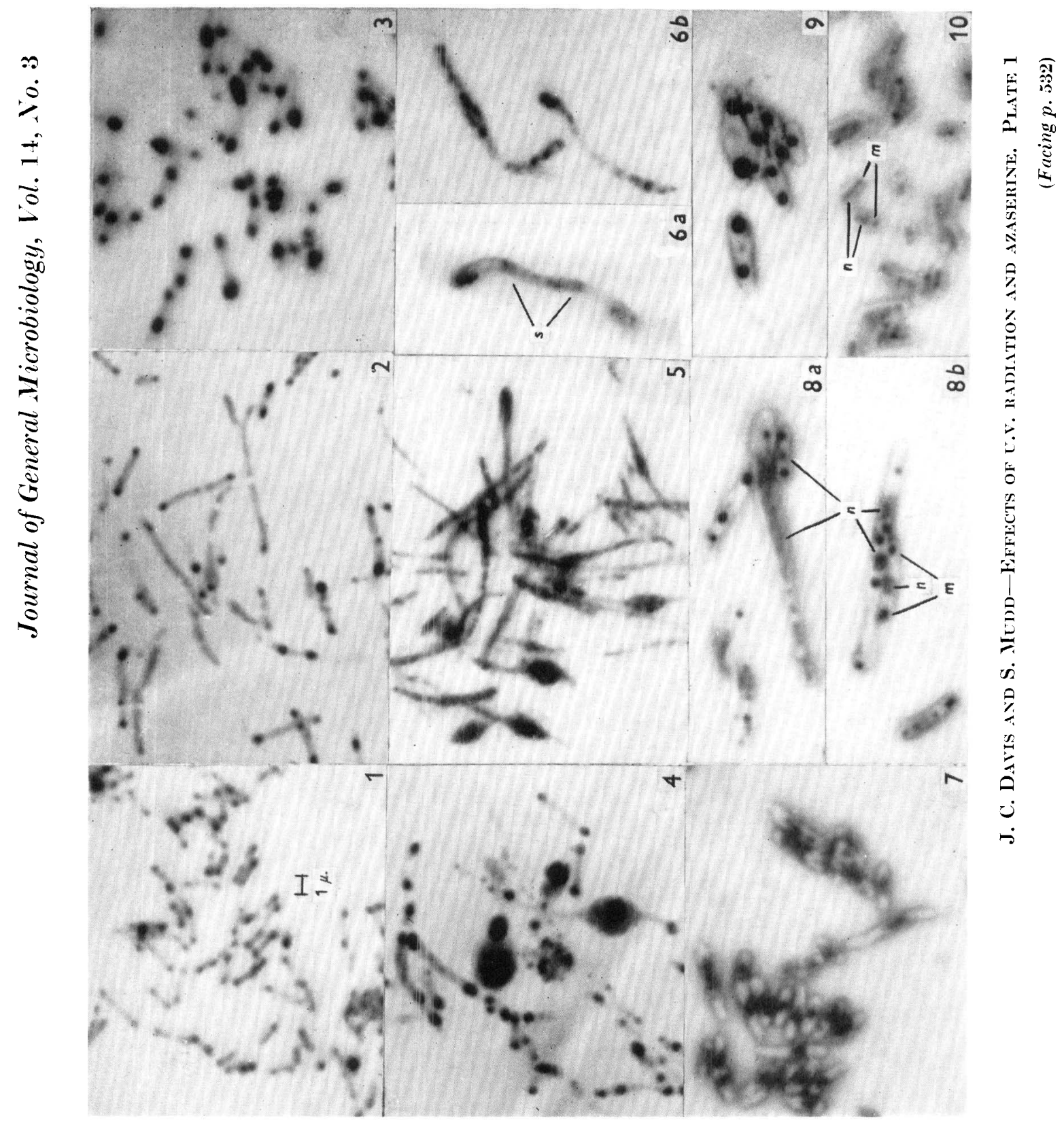

